\title{
Mineralization of Quinoline by BDD Anodes: Variable Effects and Its Effluent Characteristics
}

\author{
C. R. Wang, J. Wang, X. G. Ma, H. Li, and S. Z. Zhang \\ School of Chemical and Environmental Engineering, China University of Mining and Technology, Beijing, Beijing 100083, China
}

Correspondence should be addressed to C. R. Wang; wcrzgz@126.com

Received 30 December 2014; Accepted 22 January 2015

Academic Editor: Jian Lu

Copyright (C) 2015 C. R. Wang et al. This is an open access article distributed under the Creative Commons Attribution License, which permits unrestricted use, distribution, and reproduction in any medium, provided the original work is properly cited.

BDD anodes were selected for quinoline mineralization and influence of operating parameters, such as current density, initial quinoline concentration, supporting electrolyte, and initial $\mathrm{pH}$ was investigated. Based on the consideration of quinoline removal efficiency and average current efficiency, at initial quinoline concentration of $50 \mathrm{mg} \mathrm{L}^{-1}$ and $\mathrm{pH}$ of 7 , the optimal condition was confirmed as current density of $75 \mathrm{~mA} \mathrm{~cm}^{-2}$, electrolysis time of $1.5 \mathrm{~h}$, and $\mathrm{Na}_{2} \mathrm{SO}_{4}$ concentration of $0.05 \mathrm{~mol} \mathrm{~L}^{-1}$ by orthogonal test. At different electrolysis time, its effluent characteristics were focused on. The biodegradability (the ratio between $\mathrm{BOD}_{5}$ and COD) was enhanced from initial 0.02 to 0.57 at $90 \mathrm{~min}$. The specific oxygen uptake rate was used to assess effluent toxicity, and the value gradually reduced with decreasing effluent organic concentration with mean value of 5.51, 4.19, and $2.20 \mathrm{mgO}_{2} \mathrm{~g}^{-1} \mathrm{MLSS}_{\text {at }}$ electrolysis time of 15,30 , and $45 \mathrm{~min}$, respectively. Compared with control sample (prepared with glucose), the effluent of quinoline mineralization showed obvious inhibition effect on microorganisms at electrolysis time of $15 \mathrm{~min}$, and then it was significantly faded at $30 \mathrm{~min}$ and $45 \mathrm{~min}$

\section{Introduction}

Quinoline, as a typical heterocyclic aromatic hydrocarbon, is mainly derived from coal coking and coal gasification. Because of its pollution persistence and endocrine disturbance, it has been listed as priority pollutant by US Environmental Protection Agency (EPA) [1]. Therefore, the quinoline from coking wastewater and coal gasification wastewater should be removed efficiently. However, the practice shows that the coal coking wastewater and coal gasification wastewater containing heterocyclic aromatic hydrocarbons, such as quinoline, are characteristics of poor biodegradability and not helpful for advanced biological treatment [2]. So advanced oxidation processes (AOPs), such as Fenton oxidation, ozonation, wet air oxidation, and electrochemical oxidation, must be considered as possible methods for enhancement of biodegradability. In the above methods, electrochemical oxidation using boron-doped diamond (BDD) appears to be the most suitable technology because of its extremely wide potential window and very low background current [3-5]. Moreover, it has been used for the degradation of different organic pollutants, such as phenol and its derivatives [6-9], oxalic and oxamic acids [10], salicylic acid [11], sulfanilic acid [12], carmoisine [13], tetrahydrofuran [14], and phenanthrene and cyclodextrin [15]. In conclusion, the above organics degrading by BDD anodes mainly focused on the following four aspects: (1) investigating variable effects; for example, Rabaaoui and Allagui discussed the variable effects of salicylic acid oxidation by BDD anodes in the $\mathrm{pH}$ range 3.0-10.0 and different current density and focused on the oxidation products [11]; (2) identifying oxidation pathway; for example, Zhu et al. investigated the oxidation mechanisms of $p$-substituted phenols at BDD anodes [16]; (3) exploring degradation kinetics; for example, Díaz et al. discussed the kinetics of electrooxidation of ammonia, nitrites, and COD from aquaculture saline water system using BDD anodes and found that the ammonia removal was described by a second-order kinetics, while COD and nitrite removal followed zeroth-order kinetics [17]; (4) comparing the organics removal efficiency between BDD anodes and other electrode materials; for example, Bagastyo et al. investigated the electrochemical oxidation of reverse osmosis concentrate on Ti/ $\mathrm{Pt}-\mathrm{IrO}_{2}, \mathrm{Ti} / \mathrm{SnO}_{2}-\mathrm{Sb}$, and $\mathrm{BDD}$ anodes and 
found that dissolved organic carbon removal was enhanced at $\mathrm{BDD}$ anodes in the presence of $\mathrm{SO}_{4}{ }^{2-}[18]$.

In this paper, one of the aims was to determine main variable effects and their optimal conditions for quinoline mineralization using BDD anodes. However, the difference from previous research was that variable effects considered not only the pollutant removal efficiency but also the average current efficiency. More importantly, its effluent characteristics including the biodegradability and microbial toxicity were focused on at different electrolysis time. And the results will help to gain basic reference for selecting advanced treatment technology for quinoline wastewater.

\section{Materials and Methods}

2.1. Electrolytic System and Chemicals. The electrochemical oxidation of quinoline was carried out in a $3 \mathrm{~L}$ electrolysis cell equipped with a magnetic stirrer and direct current (DC) power supply. The BDD anodes were purchased from the company of CONDIAS GmbH with electrode size of $195 \mathrm{~mm} \times 26 \mathrm{~mm} \times 2 \mathrm{~mm}$ (length $\times$ width $\times$ thickness), and 312 stainless steel plates were used as cathodes with $1.0 \mathrm{~cm}$ of interelectrode gap.

Methanol and acetic acid used as mobile phase in HPLC were purchased from Dikma. Quinoline used was purchased from Sigma. All other chemicals used for the preparation of quinoline wastewater and other studies were of analytical grade with more than $99 \%$ purity. And water used for solution preparation was ultrapure water with resistivity of $18.2 \mathrm{M} \Omega \mathrm{cm}$.

2.2. Instruments and Analytical Methods. The $\mathrm{pH}$ of solution was determined using a pH meter (HQ30d-PHC101, HACH, USA). COD was measured by a COD meter (ET99722, Hanna Corporation, Italy). Total organic carbon (TOC) was monitored with TOC/TN meter (multi N/C 2100, Analytik Jena AG Corporation, Germany). $\mathrm{BOD}_{5}$ was determined employing the dilution inoculation method [19]. Quinoline concentration was quantified by HPLC (LC-10Avp Plus, Shimadzu, Japan) with column of Wondasil C18 $(4.6 \mathrm{~mm} \times 150 \mathrm{~mm}$, $5 \mu \mathrm{m})$. The mobile phase was composed of methanol, water, and acetic acid $(50: 49: 1, \mathrm{v} / \mathrm{v})$ with flow rate of $0.4 \mathrm{~mL} / \mathrm{min}$. Quinoline was detected at $280 \mathrm{~nm}$. The concentration of mixed liquid suspended solids (MLSS) was determined by the gravimetric method [16]. Dissolved oxygen (DO) was detected by a DO meter (LDO10103, HACH, USA). The average current efficiency (ACE) was calculated using the following equation [20]:

$$
\mathrm{ACE}=\frac{4 F V\left[(\mathrm{COD})_{0}-(\mathrm{COD})_{t}\right]}{32 I t},
$$

where $F$ is the Faraday constant $\left(96487 \mathrm{C} \mathrm{mol}^{-1}\right), V$ is volume of treated wastewater (in $\mathrm{L}),(\mathrm{COD})_{0}$ is initial COD concentration (in $\left.\mathrm{g} \mathrm{L}^{-1}\right),(\mathrm{COD})_{t}$ is $\mathrm{COD}$ concentration at time $t$ (in $\mathrm{g} \mathrm{L}^{-1}$ ), $I$ is current (in A), $t$ is time (in s), 4 is number of exchanged electrons for the electrochemical oxidation of COD, and 32 is molecular mass of $\mathrm{O}_{2}\left(\right.$ in $\mathrm{g} \mathrm{mol}^{-1}$ ).

\section{Results and Discussion}

\subsection{Effect of Operating Parameters on \\ Quinoline Mineralization}

3.1.1. Effect of Current Density. Current density is an important factor affecting the electrolysis kinetics and process economics. It corresponds to the ratio between the applied current and the surface of the working electrode [11]. As can be seen in Figure 1, at initial quinoline concentration of $50 \mathrm{mg} \mathrm{L}^{-1}, \mathrm{Na}_{2} \mathrm{SO}_{4}$ concentration of $0.05 \mathrm{~mol} \mathrm{~L}^{-1}$, and initial $\mathrm{pH}$ of 7 , when current density was variable with its value of $25,50,75$, and $100 \mathrm{~mA} \mathrm{~cm}^{-2}$, respectively, the impacts on quinoline and TOC removal were analyzed. The results showed that, with increasing of current density, removal efficiency of quinoline and TOC significantly increased. At current density of $100 \mathrm{~mA} \mathrm{~cm}^{-2}$ and electrolysis time of two hours, mineralization rate of quinoline was approximately up to $96.2 \%$; however, removal efficiency of TOC was only $80.0 \%$. The reason that, with increasing current density, the higher the concentration of ${ }^{\circ} \mathrm{OH}$ produced by $\mathrm{BDD}$ anodes, the more the quinoline oxidized by ${ }^{\circ} \mathrm{OH}$ was confirmed, but when current density was high enough, removal efficiency of TOC was more slowly enhanced than degradation rate of quinoline, which resulted from that in the mineralization process of quinoline; it transferred to other intermediate products; as a consequence, the concentration of quinoline decreased, but these intermediate products had not been further mineralized.

3.1.2. Effect of Initial Quinoline Concentration. The influence of initial quinoline concentration on its mineralization process was also investigated. To do this, solutions containing $50 \mathrm{mg} \mathrm{L}^{-1}, 80 \mathrm{mg} \mathrm{L}^{-1}$, and $100 \mathrm{mg} \mathrm{L}^{-1}$ of this compound were comparatively degraded by $\mathrm{BDD}$ anodes at $\mathrm{Na}_{2} \mathrm{SO}_{4}$ of $0.05 \mathrm{~mol} \mathrm{~L}^{-1}$, initial $\mathrm{pH}$ of 7 , and current density of $75 \mathrm{~mA} \mathrm{~cm}^{-2}$. Figure 2 shows that, at initial quinoline concentration of $50 \mathrm{mg} \mathrm{L}^{-1}$ and electrolysis time of two hours, removal efficiency of quinoline and TOC was up to $96.6 \%$ and $79.2 \%$, respectively. However, when initial quinoline concentration was improved to $100 \mathrm{mg} \mathrm{L}^{-1}$, the above value was $94.2 \%$ and $77.5 \%$, respectively. It also could be seen that, with the increasing of initial quinoline concentration, removal efficiency of TOC and quinoline gradually dropped, and when the initial quinoline concentration was higher, electrochemical oxidization for quinoline was significantly inhibited which is because when current density, electrolyte concentration, electrolysis time, and initial $\mathrm{pH}$ were constant, the quantity of ${ }^{\circ} \mathrm{OH}$ produced on the surface of electrode was also constant. Therefore, at lower initial pollutant concentration, ${ }^{\circ} \mathrm{OH}$ produced on the surface of electrode could completely react with quinoline at shorter electrolysis time. However, at higher quinoline concentration, ${ }^{\circ} \mathrm{OH}$ was relatively not enough for oxidizing quinoline and its intermediates, resulting in a decrease in mineralization efficiency.

3.1.3. Effect of Electrolyte Type. Under the conditions of initial quinoline concentration of $50 \mathrm{mg} \mathrm{L}^{-1}$, current density of 


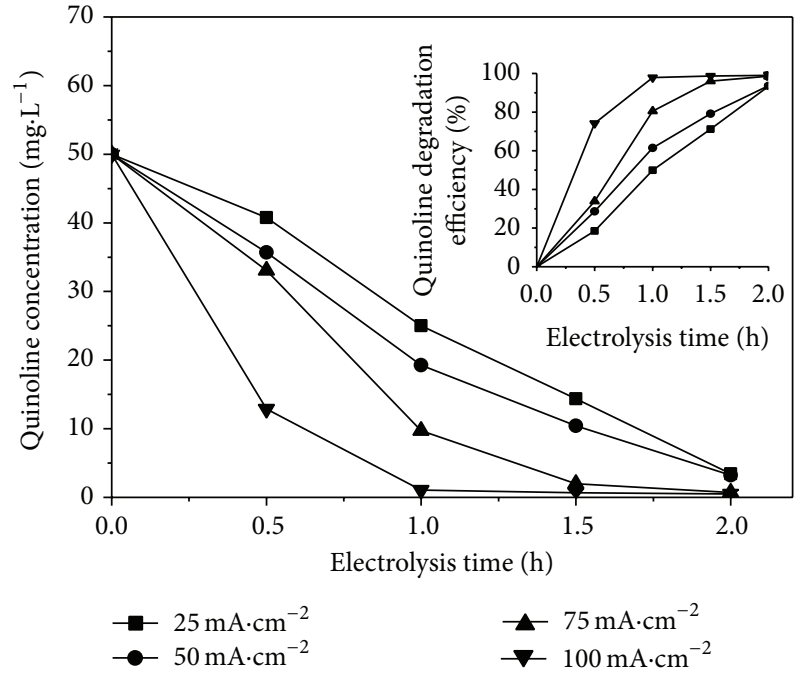

(a)

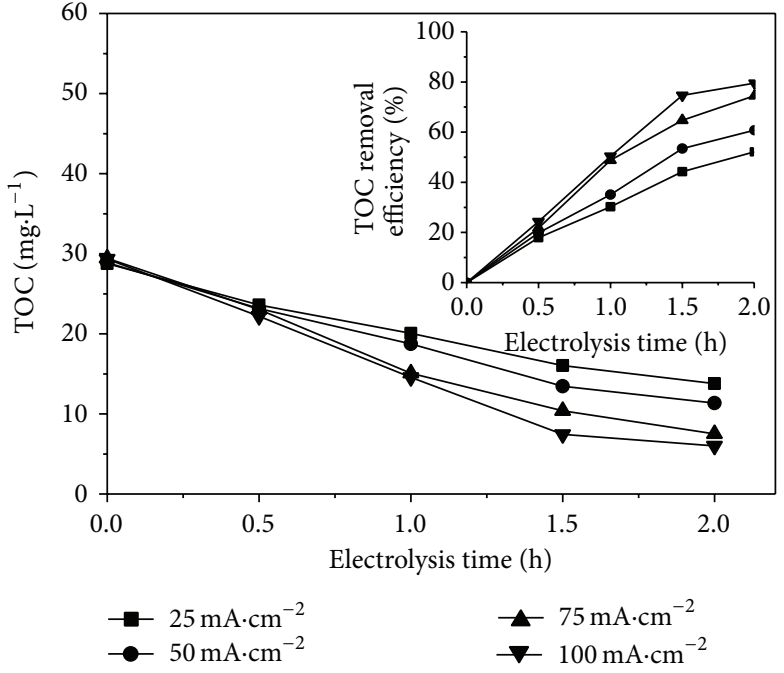

(b)

FIGURE 1: Effect of current density on quinoline degradation (a) and TOC removal (b).

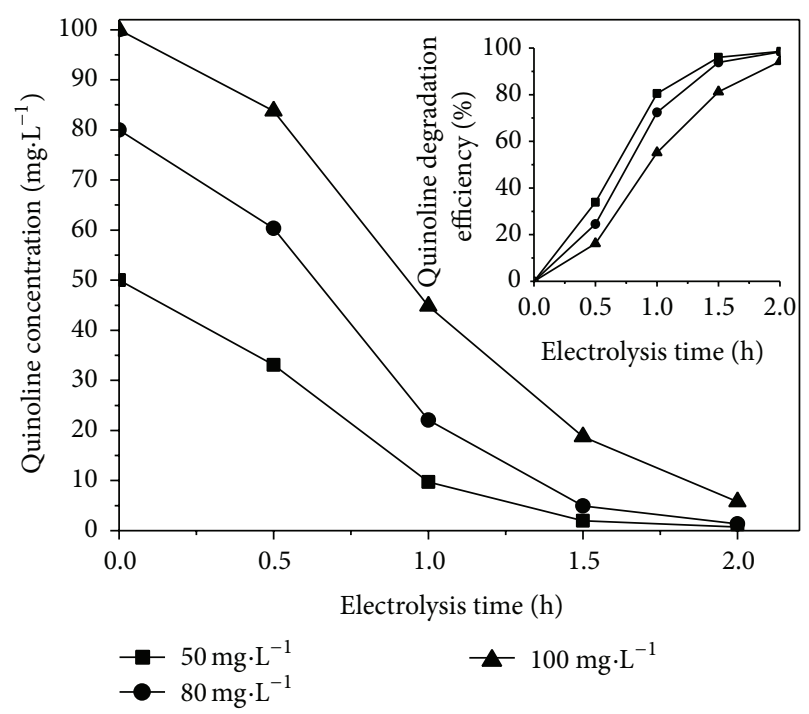

(a)

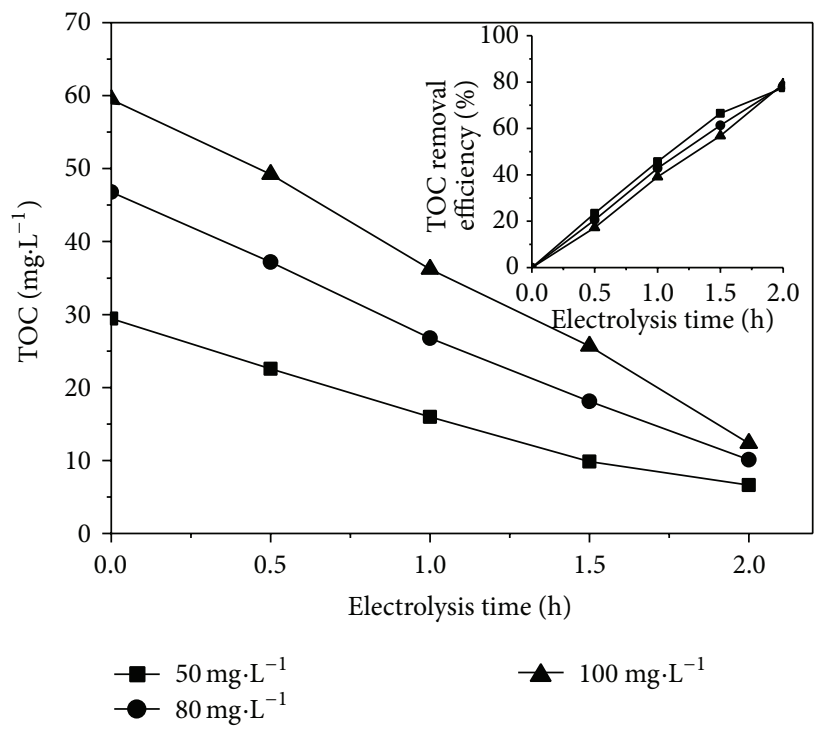

(b)

FIGURE 2: Effect of initial mass concentration on quinoline degradation (a) and TOC removal (b).

$75 \mathrm{~mA} \mathrm{~cm}^{-2}$, and initial $\mathrm{pH}$ of 7, different kinds of electrolytes with same molar concentration of $0.05 \mathrm{~mol} \mathrm{~L}^{-1}$, including $\mathrm{Na}_{2} \mathrm{SO}_{4}, \mathrm{NaCl}, \mathrm{Na}_{2} \mathrm{CO}_{3}$, and $\mathrm{NaHCO}_{3}$, were added into BDD system, and the influence was observed from Figure 3.

As shown in the figure, the highest quinoline removal efficiency was obtained at electrolytes of $\mathrm{Na}_{2} \mathrm{SO}_{4}$ with its value of $96.6 \%$; the reason for this phenomenon is that $\mathrm{Na}_{2} \mathrm{SO}_{4}$ will not involve oxidizing organic substances in the process of electrolysis. However, $\mathrm{NaCl}$ participates in the degrading reaction and produces $\mathrm{Cl}_{2}$ at anode, which further reacts with $\mathrm{H}_{2} \mathrm{O}$ and forms $\mathrm{HClO}$. So $\mathrm{NaCl}$ selected as electrolyte is helpful for ammonia removal [21], but no proof showed that it could accelerate quinoline mineralization. In contrast, the existence of the above matters would decrease the current efficiency. Additionally, compared with $\mathrm{Na}_{2} \mathrm{SO}_{4}$ as electrolyte, the quinoline removal efficiency was also lower at $\mathrm{Na}_{2} \mathrm{CO}_{3}$ or $\mathrm{NaHCO}_{3}$ as electrolytes, which was attributed to the fact that both $\mathrm{CO}_{3}{ }^{2-}$ and $\mathrm{HCO}_{3}{ }^{-}$could consume ${ }^{\circ} \mathrm{OH}$; namely,

$$
\begin{aligned}
& \cdot \mathrm{OH}+\mathrm{CO}_{3}{ }^{2-} \longrightarrow \mathrm{OH}^{-}+\mathrm{HCO}_{3}{ }^{-} \\
& \cdot \mathrm{OH}+\mathrm{HCO}_{3}{ }^{-} \longrightarrow \mathrm{H}_{2} \mathrm{O}+\mathrm{CO}_{3}{ }^{-} \cdot
\end{aligned}
$$

Thus $\mathrm{Na}_{2} \mathrm{CO}_{3}$ and $\mathrm{NaHCO}_{3}$ were able to cut down concentration of ${ }^{\circ} \mathrm{OH}$ in wastewater and then declined 


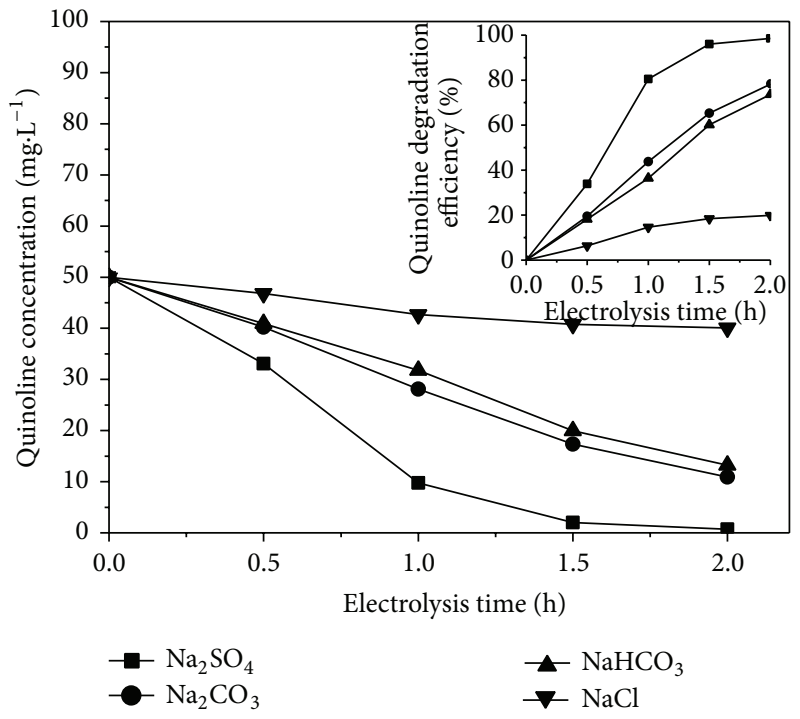

(a)

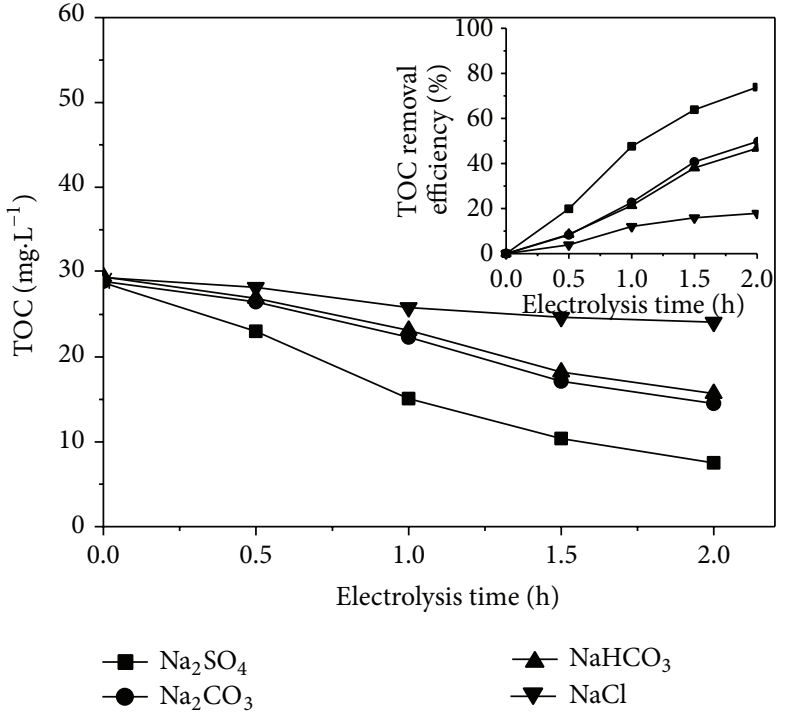

(b)

FIGURE 3: Effect of electrolyte type on quinoline degradation (a) and TOC removal (b).

quinoline removal efficiency. Therefore, in this paper, $\mathrm{Na}_{2} \mathrm{SO}_{4}$ was selected as optimal electrolyte.

3.1.4. $\mathrm{pH}$ Dependence. Due to the fact that initial $\mathrm{pH}$ can exert a significant influence on the generation of hydroxyl radicals, a solution with $50 \mathrm{mg} \mathrm{L}^{-1}$ of quinoline was electrolyzed at initial pH 5.0, 6.0, 7.0, 8.0, and 9.0, with $\mathrm{Na}_{2} \mathrm{SO}_{4}$ concentration of $0.05 \mathrm{~mol} \mathrm{~L}^{-1}$, current density of $75 \mathrm{~mA} \mathrm{~cm}^{-2}$, and electrolysis time of two hours. As shown in Figure 4, the removal efficiencies of quinoline and TOC were better in the slight alkaline medium; especially, at $\mathrm{pH}$ of 9, quinoline and TOC removal efficiency were $99.2 \%$ and $80.8 \%$, respectively, which was attributed to that negative charge existed on the surface of the electrode in the slight alkaline medium; $\mathrm{OH}^{-}$ is absorbed in the close layer of the electric double layer; as the outer layer of electrodes reacts, active oxygen in the metal crystal lattice will oxidize $\mathrm{OH}^{-}$, thus resulting in electron transfer and then producing a large number of ${ }^{\circ} \mathrm{OH}$; namely,

$$
\begin{gathered}
\mathrm{H}_{2} \mathrm{O}-\mathrm{e} \longrightarrow{ }^{\bullet} \mathrm{OH}+\mathrm{H}^{+} \\
\mathrm{OH}^{-}-\mathrm{e} \longrightarrow{ }^{\bullet} \mathrm{OH}
\end{gathered}
$$

In addition, at different $\mathrm{pH}$ values, the dissociation constant of quinoline also varies [22]. At neutral or alkaline medium, quinoline mainly appears in solution as ion, but at acidic medium, quinoline exists in the form of molecule. As we all know, the electrophilic reaction occurs more easily for ion substance than for molecular substance.

3.1.5. Orthogonal Experiment for Quinoline Removal and Average Current Efficiency. The above factors' experimental results showed that, at specific initial quinoline concentration, electrolysis time, current density, electrolyte type, and initial $\mathrm{pH}$, all factors had influence on quinoline removal, in which $\mathrm{Na}_{2} \mathrm{SO}_{4}$ was confirmed as optimal electrolyte and $\mathrm{pH}$ showed better quinoline removal in the slight alkaline medium. However, compared with the results at $\mathrm{pH}$ of 9 and $\mathrm{pH}$ of 7 , it was found that $\mathrm{pH}$ had slightly influence on quinoline removal at higher $\mathrm{pH}$. Therefore, at initial quinoline concentration of $50 \mathrm{mg} \mathrm{L}^{-1}$ and $\mathrm{pH}$ of 7, electrolysis time, current density, and $\mathrm{Na}_{2} \mathrm{SO}_{4}$ concentration would play major roles for quinoline removal. Thus the orthogonal test $\mathrm{L}_{9}(3)^{3}$ table was designed to confirm the optimal electrolysis condition (Table 1). Meanwhile average current efficiency, as an important index for evaluating electrode property, was also calculated (based on (1)), and the results are shown in Table 2.

According to Table 2, in terms of quinoline removal, electrolysis time $(B)$ extends the most significant effect and the order of significant effect on quinoline removal efficiency was electrolysis time $(B)>$ current density $(A)>\mathrm{Na}_{2} \mathrm{SO}_{4}$ concentration $(C)$. However, in terms of average current efficiency, current density $(A)$ extends the most significant effect and the order of significant effect on average current efficiency was current density $(A)>\mathrm{Na}_{2} \mathrm{SO}_{4}$ concentration (C) $>$ electrolysis time $(B)$. Taking the above-mentioned two facts into consideration, a compromised optimal condition was selected as $A_{2} B_{2} C_{3}$, namely, current density of $75 \mathrm{~mA} \mathrm{~cm}^{-2}$, electrolysis time of $1.5 \mathrm{~h}$, and $\mathrm{Na}_{2} \mathrm{SO}_{4}$ concentration of $0.05 \mathrm{~mol} \mathrm{~L}^{-1}$ with quinoline removal efficiency of $85.9 \%$ and average current efficiency of $4.17 \times 10^{-2}$.

\subsection{Effluent Characteristics of Quinoline Mineralization by BDD Anodes}

3.2.1. Variation of $\mathrm{BOD}_{5} / \mathrm{COD}$. The $\mathrm{COD}$ and $\mathrm{BOD}_{5}$ of quinoline mineralization by BDD anodes were measured every 15 minutes under the above optimal conditions (Figure 5). As the electrolysis time increased, $\mathrm{BOD}_{5}$ of effluent gradually 


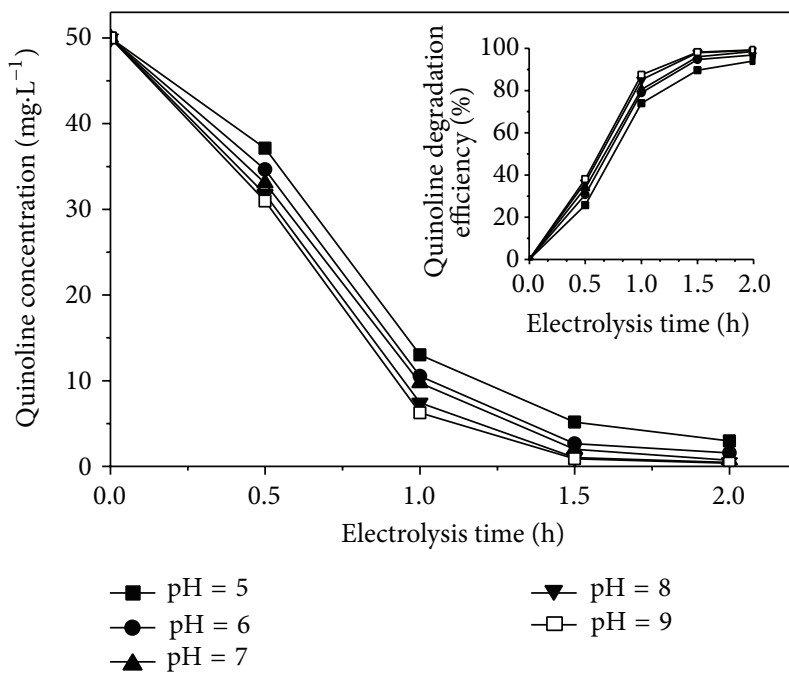

(a)

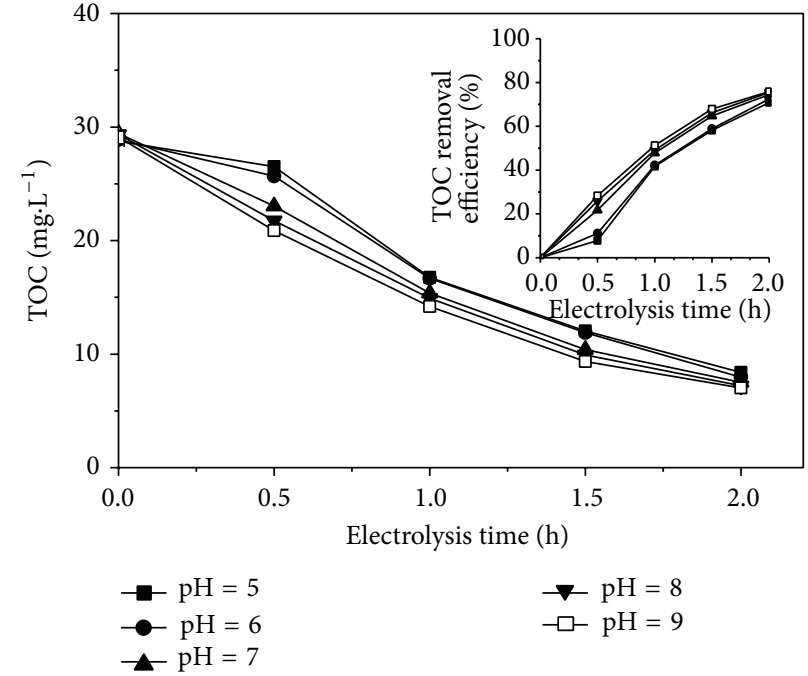

(b)

FIGURE 4: Effect of $\mathrm{pH}$ on quinoline degradation (a) and TOC removal (b).

TABLE 1: Factors and levels of orthogonal test.

\begin{tabular}{lccc}
\hline Levels & & Variables & \\
& $A$ (current density) $\left(\mathrm{mA} \mathrm{cm}^{-2}\right)$ & $B($ electrolysis time $)(\mathrm{h})$ & $C\left(\mathrm{Na}_{2} \mathrm{SO}_{4} \mathrm{concentration}\left(\mathrm{mol} \mathrm{L}^{-1}\right)\right.$ \\
\hline 1 & 50 & 1.0 & 0.03 \\
3 & 75 & 1.5 & 0.04 \\
& 100 & 2.0 & 0.05 \\
\hline
\end{tabular}

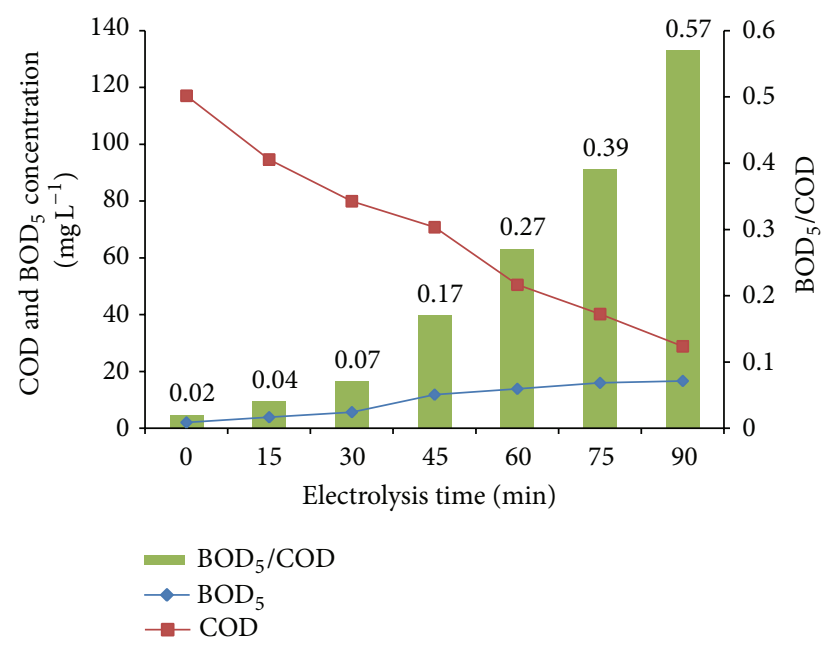

Figure 5: $\mathrm{COD}, \mathrm{BOD}_{5}$, and $\mathrm{BOD}_{5} / \mathrm{COD}$ of quinoline effluent at different electrolysis time.

increased from an initial value of $2.02 \mathrm{mg} \mathrm{L}^{-1}$ to $16.61 \mathrm{mg} \mathrm{L}^{-1}$ at $1.5 \mathrm{~h}$, and the COD of effluent gradually declined from an initial value of $117.1 \mathrm{mg} \mathrm{L}^{-1}$ to $28.8 \mathrm{mg} \mathrm{L}^{-1}$ at $1.5 \mathrm{~h}$. Meanwhile, the $\mathrm{BOD}_{5} / \mathrm{COD}$ ratio increased from an initial value of 0.02 to 0.57 at $90 \mathrm{~min}$, which indicates that the biodegradability of quinoline effluent increased with electrolysis time.
3.2.2. Variation of SOUR. The specific oxygen uptake rate (SOUR) can be used in a simple static test to assess the composition stability and toxicity of wastewater [23, 24]. Therefore, the effluent SOUR values of quinoline mineralization by BDD anodes were measured at 15, 30, and $45 \mathrm{~min}$ under the above optimal conditions. Based on the methods in [25], the activated sludge from an in-service sequencing batch reactor for domestic wastewater treatment was inoculated in the above effluent and control sample with same COD concentration (prepared with glucose), and the SOUR value of activated sludge was calculated (shown in Table 3 and Figures S1, S2, and S3 in Supplementary Material available online at http://dx.doi.org/10.1155/2015/617850). The value gradually reduced with decreasing effluent organic concentration. At $15 \mathrm{~min}$, microorganisms were obviously inhibited by quinoline effluent organic pollutants with the average SOUR being $5.51 \mathrm{mgO}_{2} \mathrm{~g}^{-1}$ MLSS. At the same time, a control sample had an SOUR of $7.01 \mathrm{mgO}_{2} \mathrm{~g}^{-1}$ MLSS. At $30 \mathrm{~min}$, the inhibition effect had decreased, with the average SOUR being $4.19 \mathrm{mgO}_{2} \mathrm{~g}^{-1}$ MLSS for the quinoline effluent sample and $5.10 \mathrm{mgO}_{2} \mathrm{~g}^{-1}$ MLSS for the control sample. At $45 \mathrm{~min}$, the inhibition effect was only slight, with the average SOURs being 2.20 and $2.58 \mathrm{mgO}_{2} \mathrm{~g}^{-1}$ MLSS for the quinoline effluent sample and control sample, respectively. The above results again indicate that the biodegradability of quinoline effluent increased and the toxicity reduced with increasing electrolysis time. 
TABLE 2: $\mathrm{L}_{9}(3)^{3}$ orthogonal test results.

\begin{tabular}{|c|c|c|c|c|c|c|}
\hline Number & $\begin{array}{l}A \text { (current density) } \\
\left(\mathrm{mA} \mathrm{cm}^{-2}\right)\end{array}$ & \multicolumn{2}{|c|}{$B$ (electrolysis time) (h) } & $\begin{array}{c}\mathrm{C} \\
\left(\mathrm{Na}_{2} \mathrm{SO}_{4} \text { concentration }\right) \\
\left(\mathrm{mol} \mathrm{L}^{-1}\right)\end{array}$ & $\begin{array}{l}\text { Quinoline } \\
\text { removal (\%) }\end{array}$ & $\operatorname{ACE}\left(\times 10^{-2}\right)$ \\
\hline 1 & 1 & \multicolumn{2}{|c|}{1} & 1 & 40.2 & 4.02 \\
\hline 2 & 1 & \multicolumn{2}{|c|}{2} & 2 & 61.8 & 4.22 \\
\hline 3 & 1 & \multicolumn{2}{|c|}{3} & 3 & 76.8 & 4.16 \\
\hline 4 & 2 & \multicolumn{2}{|c|}{1} & 2 & 46.3 & 3.16 \\
\hline 5 & 2 & \multicolumn{2}{|c|}{2} & 3 & 85.9 & 4.17 \\
\hline 6 & 2 & \multicolumn{2}{|c|}{3} & 1 & 91.7 & 3.36 \\
\hline 7 & 3 & \multicolumn{2}{|c|}{1} & 3 & 74.2 & 4.00 \\
\hline 8 & 3 & \multicolumn{2}{|c|}{2} & 1 & 92.7 & 3.40 \\
\hline 9 & 3 & \multicolumn{2}{|c|}{3} & 2 & 99.4 & 2.74 \\
\hline \multirow{7}{*}{$\begin{array}{l}\text { Quinoline } \\
\text { removal }\end{array}$} & $K 1$ & 178.8 & 160.6 & 224.5 & & \\
\hline & $K 2$ & 223.8 & 240.3 & 207.4 & & \\
\hline & K3 & 266.2 & 267.8 & 236.9 & & \\
\hline & $\overline{K 1}$ & 59.6 & 53.5 & 74.8 & & \\
\hline & $\overline{K 2}$ & 74.6 & 80.1 & 69.1 & & \\
\hline & $\overline{K 3}$ & 88.7 & 89.3 & 78.9 & & \\
\hline & $R$ & 29.1 & 35.7 & 9.8 & & \\
\hline \multirow{11}{*}{$\mathrm{ACE}$} & $\begin{array}{c}\text { Factors } \\
\text { Primary } \rightarrow \text { secondary }\end{array}$ & & & $B A C$ & & \\
\hline & Optimal condition & & & $A_{3} B_{3} C_{3}$ & & \\
\hline & $K 1$ & $12.40 \times 10^{-2}$ & $11.18 \times 10^{-2}$ & $10.78 \times 10^{-2}$ & & \\
\hline & $K 2$ & $10.69 \times 10^{-2}$ & $11.79 \times 10^{-2}$ & $10.12 \times 10^{-2}$ & & \\
\hline & $K 3$ & $10.14 \times 10^{-2}$ & $10.26 \times 10^{-2}$ & $12.33 \times 10^{-2}$ & & \\
\hline & $\overline{K 1}$ & $4.13 \times 10^{-2}$ & $3.73 \times 10^{-2}$ & $3.59 \times 10^{-2}$ & & \\
\hline & $\overline{K 2}$ & $3.56 \times 10^{-2}$ & $3.93 \times 10^{-2}$ & $3.37 \times 10^{-2}$ & & \\
\hline & $\overline{K 3}$ & $3.38 \times 10^{-2}$ & $3.42 \times 10^{-2}$ & $4.11 \times 10^{-2}$ & & \\
\hline & $R$ & $0.75 \times 10^{-2}$ & $0.51 \times 10^{-2}$ & $0.74 \times 10^{-2}$ & & \\
\hline & $\begin{array}{c}\text { Factors } \\
\text { Primary } \rightarrow \text { secondary }\end{array}$ & & & $A C B$ & & \\
\hline & Optimal condition & & & $A_{1} B_{2} C_{3}$ & & \\
\hline
\end{tabular}

Note: $K i(i=1,2,3)$ is the sum of tested index corresponding to the levels 1,2 , and 3 under the same factor; $k i(i=1,2,3)$ is $K i / 3(i=1,2,3) ; R$ is the difference of $k i(\max )$ and $k i(\min )$ under the same factor.

TABLE 3: SOUR of effluent at electrolysis time of $15 \mathrm{~min}, 30 \mathrm{~min}$, and $45 \mathrm{~min}$.

\begin{tabular}{|c|c|c|c|}
\hline Samples & OUR $\left(\mathrm{mg} \mathrm{L}^{-1} \min ^{-1}\right)$ & $\operatorname{MLSS}\left(\mathrm{g} \mathrm{L}^{-1}\right)$ & SOUR $\left(\mathrm{mgO}_{2} \mathrm{~g}^{-1} \mathrm{MLSS} \mathrm{h}^{-1}\right)$ \\
\hline \multicolumn{4}{|l|}{$15 \mathrm{~min}$} \\
\hline Sample 1 & 0.1739 & 1.986 & 5.25 \\
\hline Sample 2 & 0.1908 & 1.988 & 5.76 \\
\hline Control sample & 0.2307 & 1.975 & 7.01 \\
\hline \multicolumn{4}{|l|}{$30 \mathrm{~min}$} \\
\hline Sample 1 & 0.1008 & 1.396 & 4.33 \\
\hline Sample 2 & 0.0991 & 1.470 & 4.04 \\
\hline Control sample & 0.1322 & 1.554 & 5.10 \\
\hline \multicolumn{4}{|l|}{$45 \mathrm{~min}$} \\
\hline Sample 1 & 0.0865 & 2.642 & 1.96 \\
\hline Sample 2 & 0.1028 & 2.528 & 2.44 \\
\hline Control sample & 0.0946 & 2.202 & 2.58 \\
\hline
\end{tabular}

Note: OUR is oxygen uptake rate. 


\section{Conclusions}

BDD anode represented an efficient method for mineralization of quinoline, and the effect of electrolyte type showed that the excellent quinoline and TOC removal were achieved at $0.05 \mathrm{~mol} \mathrm{~L}^{-1} \mathrm{Na}_{2} \mathrm{SO}_{4}$ as electrolyte; the effect of $\mathrm{pH}$ showed that removal efficiencies of quinoline and TOC were better in the slight alkaline medium. Moreover, at initial quinoline concentration of $50 \mathrm{mg} \mathrm{L}^{-1}$ and initial $\mathrm{pH}$ of 7 , orthogonal experiment for quinoline removal and average current efficiency showed that the optimal electrolysis condition was current density of $75 \mathrm{~mA} \mathrm{~cm}^{-2}$, electrolysis time of $1.5 \mathrm{~h}$, and $\mathrm{Na}_{2} \mathrm{SO}_{4}$ concentration of $0.05 \mathrm{~mol} \mathrm{~L}^{-1}$ with quinoline removal efficiency of $85.9 \%$ and average current efficiency of $4.17 \times 10^{-2}$.

At different electrolysis time, the characteristic of quinoline effluent treated by BDD anodes was evaluated from variation of $\mathrm{BOD}_{5} / \mathrm{COD}$ and toxicity to microorganism. $\mathrm{BOD}_{5} / \mathrm{COD}$ was enhanced from initial 0.02 to 0.57 at $90 \mathrm{~min}$. The SOUR was used to assess compost stability and toxicity of wastewater, and the value gradually reduced with decreasing effluent organic concentration with mean value of 5.51, 4.19, and $2.20 \mathrm{mgO}_{2} \mathrm{~g}^{-1}$ MLSS at electrolysis time of 15,30 , and 45 min, respectively. Meanwhile, at the same COD concentration, the SOUR of control sample (prepared with glucose) was 7.01, 5.10, and $2.58 \mathrm{mgO}_{2} \mathrm{~g}^{-1} \mathrm{MLSS}$, respectively. It can be comparatively found that the effluent of quinoline mineralization showed obvious inhibition effect on microorganisms at electrolysis time of $15 \mathrm{~min}$, and then it was significantly faded at $30 \mathrm{~min}$ and $45 \mathrm{~min}$. The above results will help to gain basic reference for selecting advanced quinoline wastewater treatment technology.

\section{Conflict of Interests}

The authors declare that there is no conflict of interests regarding the publication of this paper.

\section{Acknowledgments}

This research was funded by the Fundamental Research Funds for the Central Universities (2009QH01) and the Special Research Funding for the Public Benefits Sponsored by the Ministry of Environmental Protection of China (2012467025). The anonymous reviewers are also gratefully acknowledged for their very helpful comments and suggestions.

\section{References}

[1] G. Yu, J. F. Niu, and J. Huang, Persistent Organic Pollutants, Science Press, Beijing, China, 2005.

[2] M. Zhang, J. H. Tay, Y. Qian, and X. S. Gu, "Coke plant wastewater treatment by fixed biofilm system for COD and $\mathrm{NH}_{3}-\mathrm{N}$ removal," Water Research, vol. 32, no. 2, pp. 519-527, 1998.

[3] J. Jeong, C. Kim, and J. Yoon, "The effect of electrode material on the generation of oxidants and microbial inactivation in the electrochemical disinfection processes," Water Research, vol. 43, no. 4, pp. 895-901, 2009.

[4] M. Panizza and G. Cerisola, "Application of diamond electrodes to electrochemical processes," Electrochimica Acta, vol. 51, no. 2, pp. 191-199, 2005.

[5] M. Panizza and G. Cerisola, "Electro-Fenton degradation of synthetic dyes," Water Research, vol. 43, no. 2, pp. 339-344, 2009.

[6] M. J. Pacheco, A. Morão, A. Lopes, L. Ciríaco, and I. Gonçalves, "Degradation of phenols using boron-doped diamond electrodes: a method for quantifying the extent of combustion," Electrochimica Acta, vol. 53, no. 2, pp. 629-636, 2007.

[7] A. F. Azevedo, F. A. Souza, J. T. Matsushima, M. R. Baldan, and N. G. Ferreira, "Detection of phenol at boron-doped nanocrystalline diamond electrodes," Journal of Electroanalytical Chemistry, vol. 658, no. 1-2, pp. 38-45, 2011.

[8] G. F. Pereira, L. S. Andrade, R. C. Rocha-Filho, N. Bocchi, and S. R. Biaggio, "Electrochemical determination of bisphenol A using a boron-doped diamond electrode," Electrochimica Acta, vol. 82, pp. 3-8, 2012.

[9] N. Rabaaoui, M. E. K. Saad, Y. Moussaoui, M. S. Allagui, A. Bedoui, and E. Elaloui, "Anodic oxidation of o-nitrophenol on BDD electrode: variable effects and mechanisms of degradation," Journal of Hazardous Materials, vol. 250-251, pp. 447-453, 2013.

[10] S. Garcia-Segura and E. Brillas, "Mineralization of the recalcitrant oxalic and oxamic acids by electrochemical advanced oxidation processes using a boron-doped diamond anode," Water Research, vol. 45, no. 9, pp. 2975-2984, 2011.

[11] N. Rabaaoui and M. S. Allagui, "Anodic oxidation of salicylic acid on BDD electrode: variable effects and mechanisms of degradation," Journal of Hazardous Materials, vol. 243, pp. 187192, 2012.

[12] A. El-Ghenymy, C. Arias, P. L. Cabot et al., "Electrochemical incineration of sulfanilic acid at a boron-doped diamond anode," Chemosphere, vol. 87, no. 10, pp. 1126-1133, 2012.

[13] A. Thiam, I. Sirés, J. A. Garrido, R. M. Rodríguez, and E. Brillas, "Effect of anions on electrochemical degradation of azo dye Carmoisine (Acid Red 14) using a BDD anode and air-diffusion cathode," Separation and Purification Technology, vol. 140, pp. 43-52, 2015.

[14] A. Urtiaga, P. Fernandez-Castro, P. Gómez, and I. Ortiz, "Remediation of wastewaters containing tetrahydrofuran. Study of the electrochemical mineralization on BDD electrodes," Chemical Engineering Journal, vol. 239, pp. 341-350, 2014.

[15] E. Mousset, N. Oturan, E. D. van Hullebusch, G. Guibaud, G. Esposito, and M. A. Oturan, "Treatment of synthetic soil washing solutions containing phenanthrene and cyclodextrin by electro-oxidation. Influence of anode materials on toxicity removal and biodegradability enhancement," Applied Catalysis B: Environmental, vol. 160-161, pp. 666-675, 2014.

[16] X. P. Zhu, J. R. Ni, H. N. Li, Y. Jiang, X. Xing, and A. G. Borthwick, "Effects of ultrasound on electrochemical oxidation mechanisms of $p$-substituted phenols at $\mathrm{BDD}$ and $\mathrm{PbO}_{2}$ anodes," Electrochimica Acta, vol. 55, no. 20, pp. 5569-5575, 2010.

[17] V. Díaz, R. Ibáñez, P. Gómez, A. M. Urtiaga, and I. Ortiz, "Kinetics of electro-oxidation of ammonia-N, nitrites and COD from a recirculating aquaculture saline water system using BDD anodes," Water Research, vol. 45, no. 1, pp. 125-134, 2011.

[18] A. Y. Bagastyo, D. J. Batstone, K. Rabaey, and J. Radjenovic, "Electrochemical oxidation of electrodialysed reverse osmosis 
concentrate on $\mathrm{Ti} / \mathrm{Pt}-\mathrm{IrO}_{2}, \mathrm{Ti} / \mathrm{SnO}_{2}-\mathrm{Sb}$ and boron-doped diamond electrodes," Water Research, vol. 47, no. 1, pp. 242-250, 2013.

[19] Editorial Board of Monitoring and Analysis Method of Water and Waste Water, Monitoring and Analysis Method of Water and Waste Water, China Environmental Science Press, Beijing, China, 2002.

[20] P. Cañizares, J. Lobato, R. Paz, M. A. Rodrigo, and C. Sáez, "Electrochemical oxidation of phenolic wastes with borondoped diamond anodes," Water Research, vol. 39, no. 12, pp. 2687-2703, 2005.

[21] A. Kapałka, L. Joss, Á. Anglada, C. Comninellis, and K. M. Udert, "Direct and mediated electrochemical oxidation of ammonia on boron-doped diamond electrode," Electrochemistry Communications, vol. 12, no. 12, pp. 1714-1717, 2010.

[22] M. Lapertot, P. Pichat, S. Parra, C. Guillard, and C. Pulgarin, "Photocatalytic degradation of p-halophenols in $\mathrm{TiO}_{2}$ aqueous suspensions: halogen effect on removal rate, aromatic intermediates and toxicity variations," Journal of Environmental Science and Health, Part A, vol. 41, no. 6, pp. 1009-1025, 2006.

[23] B. Scaglia, F. G. Erriquens, G. Gigliotti et al., "Precision determination for the specific oxygen uptake rate (SOUR) method used for biological stability evaluation of compost and biostabilized products," Bioresource Technology, vol. 98, no. 3, pp. 706-713, 2007.

[24] J. Yin, X. F. Wang, J. H. Wang, C. Jiao, and A. L. Zhou, "Relationships between SBR mixed liquor SOUR and control parameters," Environmental Pollution and Control, vol. 29, pp. 481-483, 2007.

[25] C. R. Wang, M. R. Zhang, W. Liu, M. Ye, and F. J. Su, "Effluent characteristics of advanced treatment for biotreated coking wastewater by electrochemical technology using BDD anodes," Environmental Science and Pollution Research, 2014. 

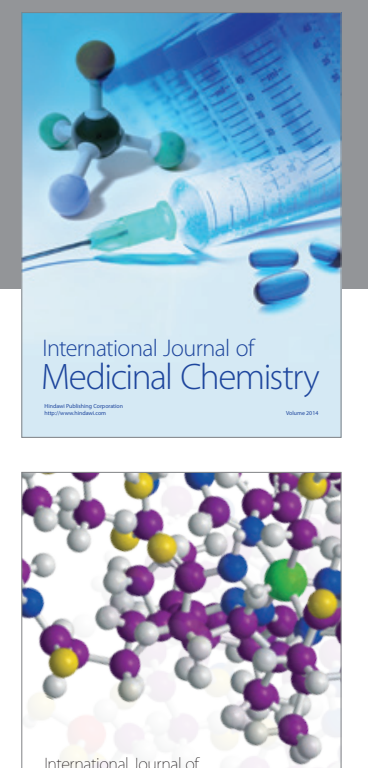

\section{Carbohydrate} Chemistry

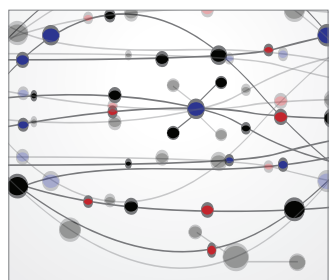

The Scientific World Journal
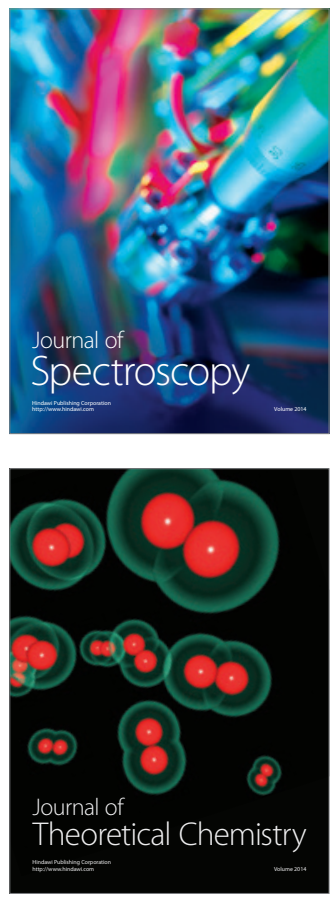
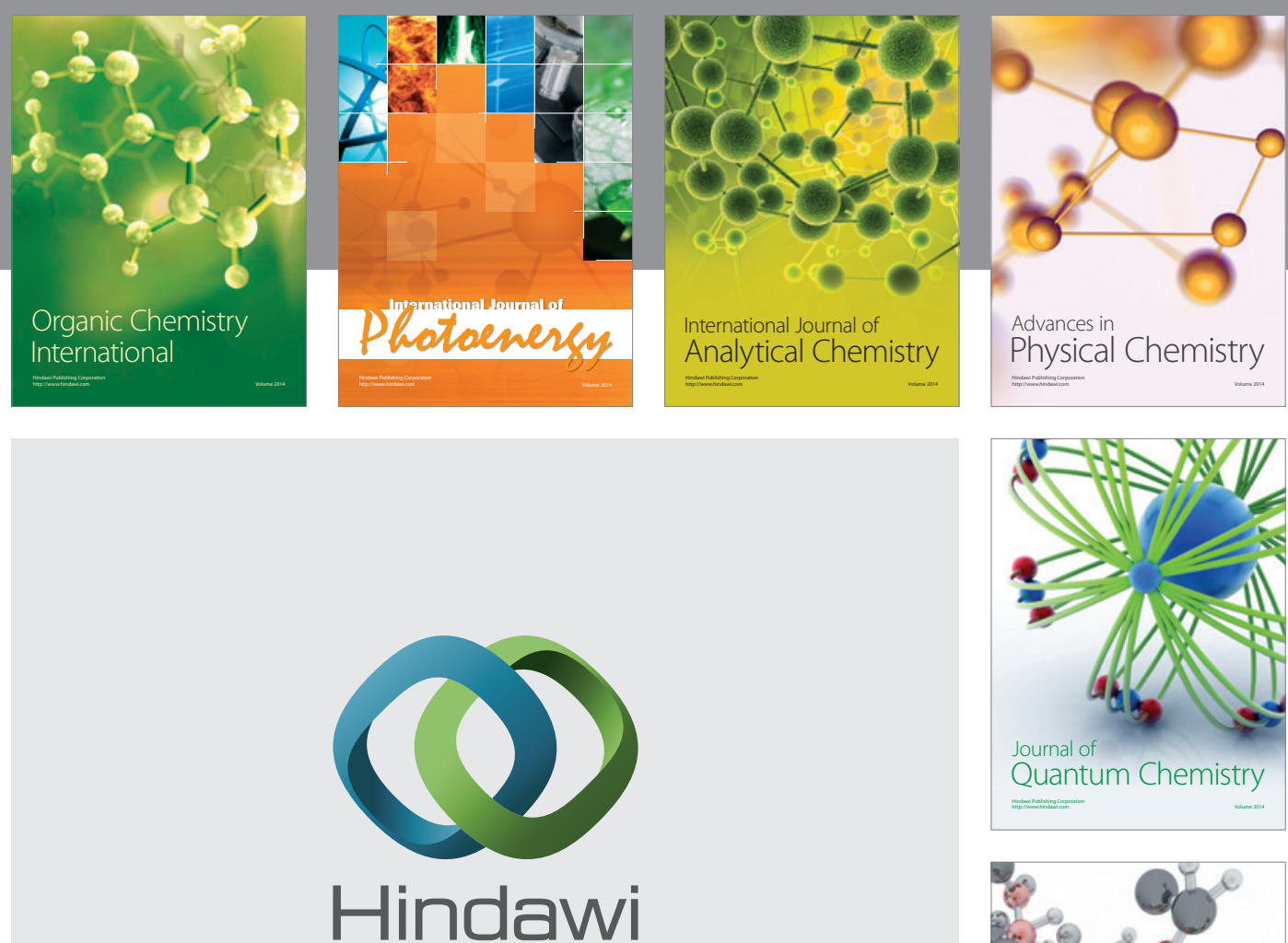

Submit your manuscripts at

http://www.hindawi.com

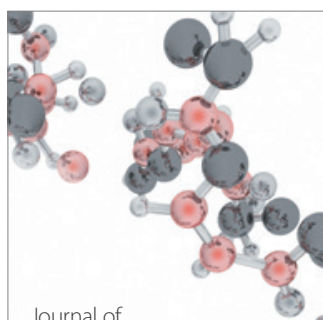

Analytical Methods

in Chemistry

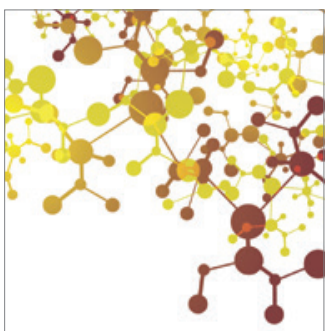

Journal of

Applied Chemistry

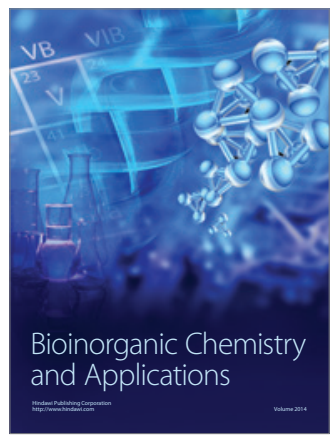

Inorganic Chemistry
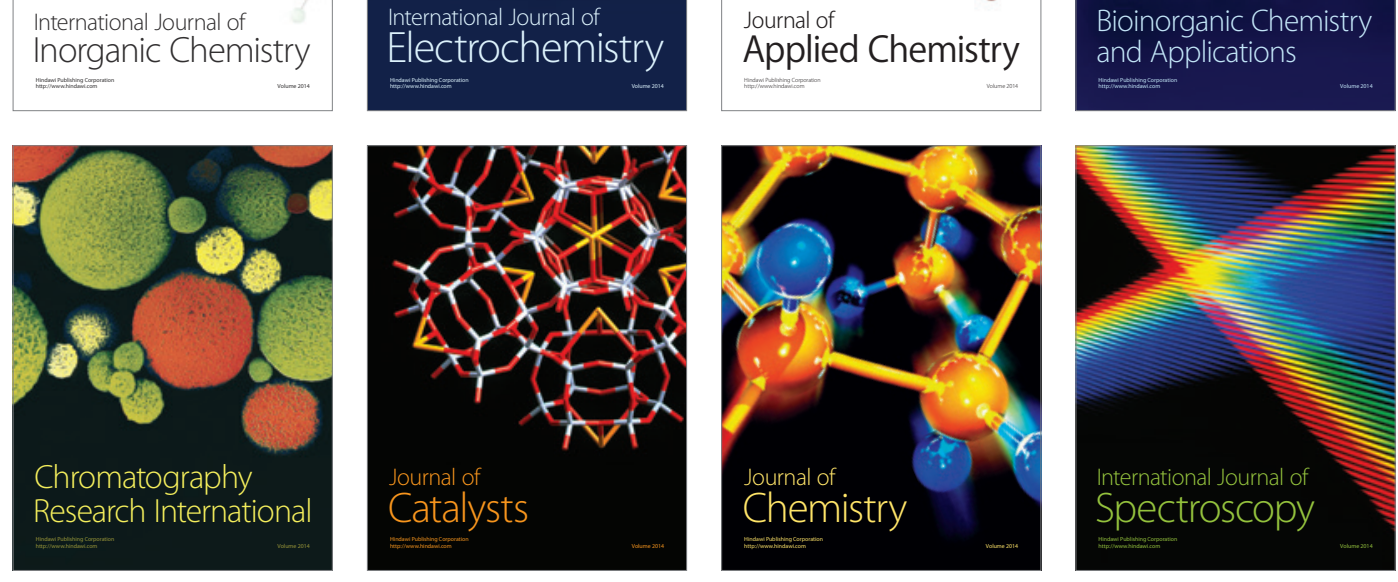